\title{
Por que é importante discutir desigualdade
}

\author{
Why Inequality Matters
}

Fernando Augusto Mansor de Mattos ${ }^{* *}$

\begin{abstract}
Resumo: O artigo destaca três motivos para explicar a crescente importância do tema da desigualdade no debate acadêmico e político das últimas décadas nos países desenvolvidos. Estes motivos são discutidos respectivamente em cada uma das três sessões em que se divide o texto. A primeira sessão destaca a dimensão econômica da desigualdade, mostrando que a ampliação da concentração da renda, desde os anos 1980, e, ainda com mais intensidade, nos anos 2000, já tem sido motivo suficiente para a retomada do tema. A segunda argumenta que, nos anos 2000, a concentração da renda tem beneficiado o " $1 \%$ do topo" da distribuição. A explicação acerca dos determinantes desse fenômeno é importante para abrir espaço para uma interpretação mais abrangente da desigualdade, incorporando aspectos políticos, sociais e institucionais ao tema, e destacando as contradições relacionadas ao fato de que a desigualdade vem se ampliando em contexto de vigência de Democracia formal nos diferentes países. A terceira sessão mostra que a interpretação da trajetória da desigualdade sob um ponto de vista multidimensional, conforme proposto anteriormente, permite compreender a natureza dos diversos aspectos de deterioração dos mercados de trabalho nas décadas recentes. A articulação dos três motivos mencionados revela a necessidade de que a desigualdade tenha uma abordagem multidisciplinar e multidimensional. As conclusões ressaltam que a compreensão acerca dos determinantes da trajetória da desigualdade, em todas as suas dimensões, permite reunir elementos para subsidiar informações para a construção de políticas públicas destinadas a enfrentar as crescentes mazelas sociais e também para discutir formas de combater a desigualdade extrema e seus eventuais efeitos deletérios sobre a própria acumulação capitalista.
\end{abstract}

Palavras-chave: Desigualdade; Distribuição de renda; $1 \%$ mais ricos. Ordem financeira internacional; Concentração da riqueza; Concentração de poder político; Democracia

\begin{abstract}
The article highlights three reasons for explaining the growing importance of inequality in the academic and political debate of recent decades in developed countries. These reasons are discussed respectively in each of the three sections in which the text is divided. The first session highlights the economic dimension of inequality, showing that the increase in income concentration since the 1980s, and even more intensely in the

\footnotetext{
* Submissão: 23/11/2019 | Aprovação: 04/05/2020 | DOI: 10.5380/re.v42i78.69859

** Professor-pesquisador do Programa de Pós-Graduação em Economia da Universidade Federal Fluminense (UFF) e professor-visitante do Programa de Pós-Graduação em Ciência Política da UFF, Brasil | E-mail: fermatt1@hotmail.com | ORCID: 0000-0002-1196-3246
} 
2000s, has already shown enough reasons for the resumption of the theme. The second session argues that, in the 2000s, income concentration has benefited the "top $1 \%$ " of the distribution. The explanation of the determinants of this phenomenon is important to make room for a broader interpretation of inequality, incorporating political, social and institutional aspects to the theme, and highlighting the contradictions related to the fact that inequality has been widening in a context of formal Democracy in different countries. The third session shows that interpreting the trajectory of inequality from a multidimensional point of view, as proposed earlier, allows us to understand the nature of the various aspects of labor market deterioration in recent decades. The articulation of the three reasons mentioned reveals the need for inequality to have a multidisciplinary and multidimensional approach. The conclusions point out that understanding the determinants of the trajectory of inequality, in all its dimensions, allows us to gather elements to support information for the construction of public policies aimed at addressing the growing social ills and to discuss ways to combat extreme inequality and its possible deleterious effects on capitalist accumulation itself.

Keywords: Inequality; Income distribution; Top 1\%. International financial order; Wealth concentration; Political power concentration; Democracy

JEL: D31; D33; E24; E25; F38; N3; N4; O16; P16 


\section{Apresentação}

"It is our job to glory in inequality and to see that talents and abilities are given vent and expression for the benefit of us all". Margaret Thatcher, primeira-ministra britânica

"[O]f the tendencies that are harmful to sound economics, the most seductive and... poisonous is to focus on questions of distribution". Robert Lucas (2004), professor de Economia de Harvard, ganhador do Prêmio Nobel

"[Those who oppose increases in incomes at the top are] spiteful egalitarians". Martin Feldstein (1998), professor de Economia de Harvard, presidente do National Bureau of Economic Research (1978-2008) e assessor econômico de Ronald Reagan

"Poverty bothers me. Inequality does not. I just don't care". Willem Buiter (2007), professor de Economia da London School of Economics

As epígrafes mencionadas acima, todas elas retiradas de Wade (2014), revelam o desmazelo com que os economistas e políticos conservadores tratam a questão da desigualdade. Por um lado, a despeito da enorme expansão da desigualdade a partir dos anos 1980 (há quase quarenta anos que a expansão da desigualdade ocorre de forma ininterrupta na quase totalidade dos países capitalistas do mundo), os conservadores insistem em negligenciar a importância do tema e de seus desdobramentos. Por outro lado, o interesse pelo assunto tem aumentado na academia e nos meios políticos, não apenas por parte de pesquisadores de formação heterodoxa (keynesianos, em sua maioria, mas marxistas também), como também por parte de autores de formação neoclássica, porém com histórico compromisso pessoal e acadêmico em favor da redução da desigualdade e da melhoria do bem estar da população, como mostram os livros recentes de Tomas Piketty $(2014,2019)$, para não falar no Prêmio Nobel Joseph Stiglitz, que tem denunciado em livros, artigos acadêmicos e em artigos de divulgação a trajetória recente da ampliação da desigualdade nos EUA e suas consequências nefastas ${ }^{1}$.

O objetivo deste artigo é defender a importância de se retomar a discussão sobre a desigualdade nas sociedades contemporâneas. As ilustrações estatísticas e

\footnotetext{
${ }^{1} \mathrm{O}$ recente debate sobre o $1 \%$ de rendas mais altas (que será tema de seção específica deste artigo) foi impulsionada por artigos de Stiglitz em jornais; seu recente livro intitulado The Price of Inequality (Stiglitz, 2013) denuncia os efeitos sociais, sob diversos pontos de vista, da expansão da desigualdade. Guimarães (2012) também vai na mesma linha.
} 
as referências bibliográficas estão baseadas especialmente em exemplos dos países desenvolvidos, mas valem também para os países subdesenvolvidos, onde esse problema é crônico e vem desde as suas próprias constituições enquanto nações. O foco principal do artigo repousará nos aspectos econômicos da desigualdade, não obstante que o debate sobre desigualdade venha, nos anos mais recentes, incorporando diversos outros aspectos que não apenas o econômico, analisando-a sob um ponto de vista multidimensional e multidisciplinar. $\mathrm{O}$ artigo está dividido em três seções, representando, respectivamente, os três motivos principais pelos quais entendemos que é importante retomar a referida discussão. Na primeira, apresenta-se uma breve descrição da trajetória da desigualdade, em sua faceta econômica, desde o pós-segunda guerra até os dias atuais. O argumento defendido é o de que, após um período em que o tema perdeu presença nos debates acadêmicos, houve uma retomada de sua aparição nas revistas acadêmicas e no debate político, em primeiro lugar, a partir dos anos 1980, quando a desigualdade econômica, depois de pouco mais de três décadas de queda (a contar do final da Segunda Guerra Mundial $^{2}$ ), voltou a se expandir nitidamente nos países desenvolvidos (com diferentes graus de intensidade). A discussão se estende até o momento atual, incorporando novas perspectivas de análise.

Na segunda seção, mostramos que o debate sobre o tema toma uma forma mais abrangente, com novos aspectos (que não os estritamente econômicos) inseridos no que chamaremos aqui de "a questão do $1 \%$ do topo"3. O "debate sobre o $1 \%$ " tem merecido destaque especial na literatura sobre a desigualdade, dada a magnitude e a natureza da escalada da desigualdade econômica desde o início dos anos 2000 e, ainda mais, após os rescaldos do que a literatura internacional chama

\footnotetext{
${ }^{2}$ Noah (2010), tomando como referência a experiência dos EUA (mas que, no caso, poderia valer também, nas linhas gerais, para os países europeus desenvolvidos), denomina os principais períodos de destacadas mudanças no perfil da distribuição de renda nos EUA. Assim, segundo o autor, The Great Compression conforma o período entre 1937 e 1967, quando as políticas do New Deal, o fortalecimento dos sindicatos de trabalhadores e a progressiva taxação tributária, em contexto de forte expansão das atividades e do emprego industriais, promoveram uma expressiva redução das desigualdades pessoais da renda no país. Por outro lado, "The Great Divergence", iniciada no final dos anos 1970, foi impulsionada exatamente pela reversão dos fatores acima mencionados, apesar de terem ocorridos períodos de expansão do PIB real desde então. Mas esta expansão tem revelado cada vez mais expressiva concentração da renda e da riqueza.

${ }^{3}$ No ano de 2011, lembra Thernborn (2013), diversos movimentos populares espoucaram pelo mundo, e em todos eles a questão da desigualdade estava subjacente. Os "Occupy Movements" nos EUA e no Reino Unido faziam alusão ao $1 \%$ mais rico e seus privilégios, denunciando que esse grupo, passados os efeitos iniciais da crise, estava absorvendo parcelas crescentes da renda e da riqueza criadas pela retomada da atividade econômica nos diferentes países, enquanto os demais $99 \%$ percebiam ou estagnação da sua renda, ou perda da mesma, no limite até mesmo de enfrentar a situação de desemprego aberto.
} 
de "A Grande Depressão" dos anos 2000, deflagrada pela crise do subprime ocorrida em 2008 nos EUA e rapidamente espalhada sobre toda a economia mundial. Ademais, a discussão sobre o "1\% mais rico" revela enorme importância pois amplia o raio da análise do tema da desigualdade, incorporando aspectos político/institucionais, sociais e geopolíticos, o que torna a discussão sobre a desigualdade crescentemente multidimensional e multidisciplinar. A terceira seção procura destacar mais um motivo pelo qual o tema da desigualdade merece ser discutido. Nessa seção, postula-se que o entendimento da natureza da trajetória recente da desigualdade (o que inclui a magnitude de sua expansão e sua composição segundo as fontes de rendimentos) ajuda a explicar as recentes transformações pelas quais tem passado o mundo do trabalho nos países centrais, situação que pode ser replicada também para os países periféricos, embora não tenhamos o objetivo de discutir, neste artigo, as especificidades desses países. Por fim, nas conclusões, pretende-se ressaltar, com base nas principais ideias relatadas e discutidas nas seções mencionadas, que a compreensão do comportamento, magnitude e composição da evolução recente da desigualdade permite reunir elementos para subsidiar informações que possibilitem construir políticas públicas para enfrentar as mazelas sociais e, no limite, para dinamizar o capitalismo contemporâneo, ou fazê-lo mudar substancialmente de feição.

\section{Linhas gerais da trajetória do perfil distributivo desde a Segunda Guerra Mundial aos dias atuais}

O objetivo desta seção é descrever como a trajetória da desigualdade de renda desde a Segunda Guerra Mundial até os dias atuais afetou e ainda tem afetado a presença do tema nos debates econômicos e na discussão acadêmica da área de Economia.

A trajetória da desigualdade econômica desde o segundo pós-guerra ostenta dois momentos marcantes. O primeiro se refere aos cerca de 35 anos após o final da Segunda Guerra (o que a literatura de História Econômica chamou de Anos Dourados do Capitalismo, conforme Hobsbawm (1995)), quando foi possível conjugar, nos países desenvolvidos, crescimento econômico com redução na desigualdade de renda. A partir do final dos anos 1970/início dos anos 1980 (dependendo do país em questão), o processo de redução da desigualdade que 
caracterizara os Anos Dourados sofre uma "virada"4 e, a partir de então, exibe uma quase contínua expansão da desigualdade. Dentro desse período, que se inicia em final dos anos 1970/início dos anos 1980, existe um novo momento, a partir dos anos 2000, quando a ascensão da desigualdade parece tomar novo impulso, não revertido nem mesmo após os rescaldos da crise de 2008 (Gráfico 1).

\footnotetext{
${ }^{4}$ A "virada" pode ser remetida ao que a literatura econômica sobre a questão da desigualdade chamou de "inversão da curva de Kuznets" (ou palavras semelhantes), referindo-se ao trabalho clássico de Kuznets (1955), que utilizou dados de uma longa série histórica (que remonta ao quarto final do século XIX e vai até os anos 1950) de renda familiar per capita referentes a três países: EUA, Reino Unido e Alemanha. Seu objetivo foi descrever como o processo de desenvolvimento econômico alterou a distribuição pessoal da renda e, para isso, tomou como referência os países acima mencionados (embora - registre-se - ele tenha ressalvado que estes exemplos históricos não deveriam ser generalizados, pois cada país teria suas especificidades). Para cumprir seu objetivo, Kuznets propôs um modelo no qual dividiu a economia em dois setores (um atrasado - o setor agrícola; e outro, moderno - o setor industrial). Seu modelo lhe permitiu descrever como a transição de uma economia de baixa renda para uma economia desenvolvida impactou no perfil distributivo, à medida que as pessoas migravam do setor mais atrasado para o mais moderno. As alterações ocorridas no perfil distributivo dependiam, segundo a formulação do autor, dos níveis iniciais e das posteriores alterações nas diferenças de renda entre os setores, das mudanças distributivas ocorridas dentro de cada setor em processo de transformação e da rapidez com que ocorria a migração dos trabalhadores do setor de mais baixa renda para o setor de renda mais elevada (moderno, ou industrializado). Basicamente, o que se conclui do modelo de Kuznets (1955) é que, em sociedades em processo de desenvolvimento econômico, a desigualdade inicialmente é baixa, aumentando à medida que a renda per capita da sociedade cresce, como resultado da interação dos elementos acima mencionados. A partir de certo ponto, porém, a desigualdade começa a declinar, quando certo grau de maturidade e desenvolvimento econômico é atingido. $\mathrm{O}$ momento em que Kuznets estava redigindo seu mencionado trabalho era justamente quando a Europa capitalista desenvolvida estava percebendo contínua e expressiva redução da desigualdade na distribuição pessoal da renda (nos EUA também, embora menos), o que parecia "confirmar" a formulação de Kuznets. De todo modo, seu trabalho revelar-se-ia seminal, gerando (até hoje) inúmeros artigos e livros que discutem a relação entre crescimento e distribuição. Os comentadores que se seguiram à publicação do referido trabalho de Kuznets (1955) cunhariam a expressão "curva do U invertido" (ou "sino de Kuznets") para descrever esse processo de aumento inicial da desigualdade, seguido de estabilização, reversão e queda da mesma, à medida que avançava o processo de crescimento econômico de um país capitalista. Nos anos 1970, ainda parecia, a muitos analistas, que aquele processo de redução das desigualdades constituir-se-ia uma norma dali em diante. A nova rodada de ampliação da desigualdade pessoal da renda, a partir dos anos 1980, tomaria a alcunha de reversão da curva da Kuznets. Ou reversão da curva do "U invertido". O "U invertido" ocorre quando se coloca no eixo das abscissas de um plano de coordenadas cartesianas o indicador do grau de desigualdade e, no eixo das ordenadas, o indicador de desenvolvimento, que pode ser a renda per capita, que cresce ao longo do tempo. Ver Palma (2011) para uma discussão detalhada.
} 


\section{Gráfico 1 - Parcela do décimo superior: Europa e Estados Unidos}

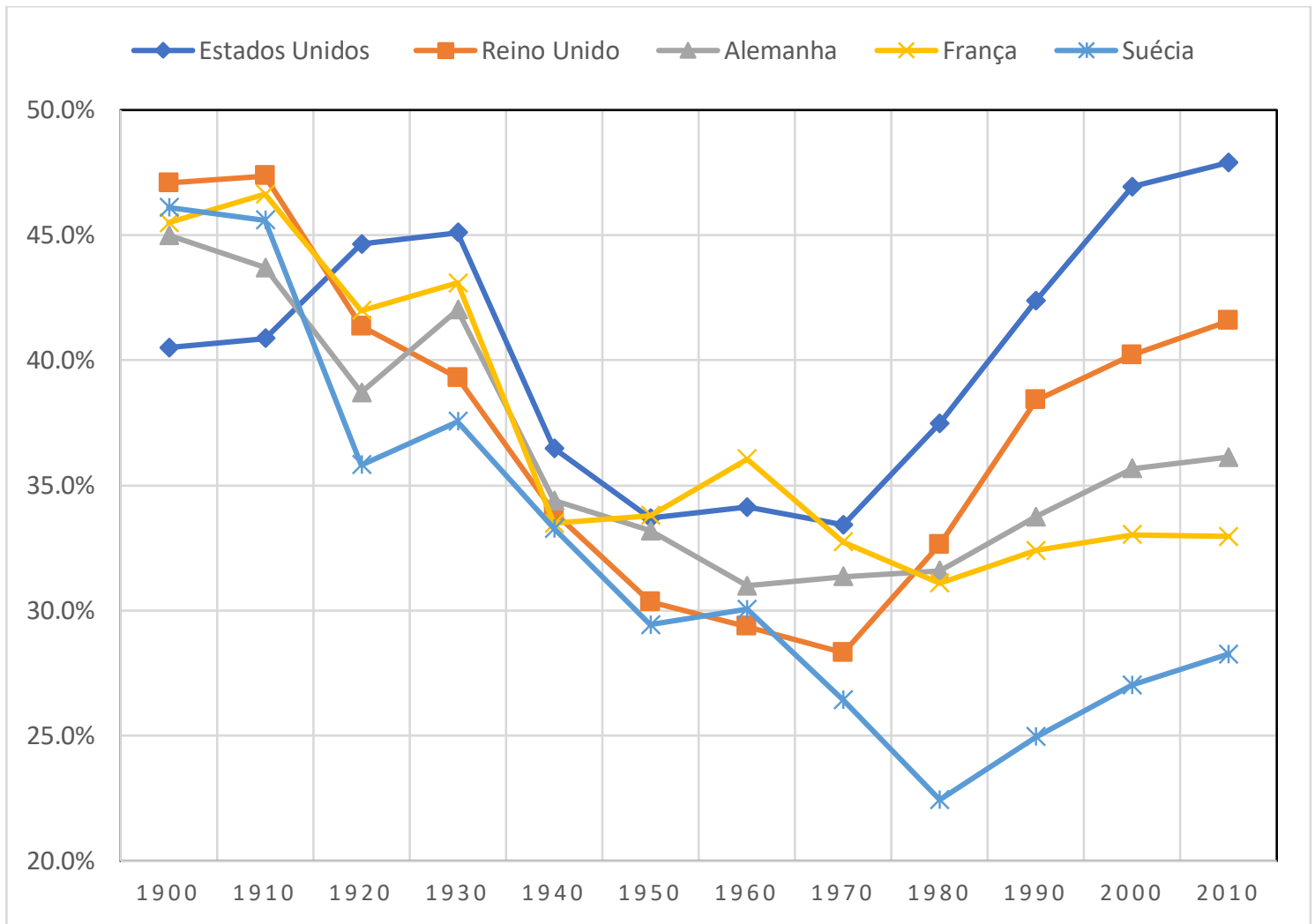

Fonte: elaboração própria a partir de apêndice disponibilizado em Piketty (2014).

O "capitalismo organizado" (Mattos, 1997) do pós-segunda guerra notabilizou-se por importante expansão da atividade produtiva ${ }^{5}$, conjugada por redução das desigualdades econômicas. Há diversos fatores ideológicos, geopolíticos, políticos, institucionais e sociais para que esse resultado tivesse sido obtido. As reminiscências da Segunda Guerra e de todo o período do entreguerras (com a Grande Depressão deflagrada em 1929, nos EUA, e espalhada pelo mundo) debilitaram a hegemonia do pensamento liberal que havia vigorado entre os conflitos, desacreditando as normas que regiam a política econômica nos mais variados países.

O cenário da Guerra Fria teve também papel preponderante para a mudança do cenário econômico, pois, terminada a aliança pontual entre EUA e países

\footnotetext{
${ }^{5}$ Inclusive com taxas de crescimento de ampliação do estoque de capital fixo que não seriam obtidas em décadas seguintes, notadamente a partir dos anos 1980. Segundo dados oficiais recolhidos em instituições financeiras internacionais em pesquisa de Bosworth e Collins (2003), a taxa média de crescimento do investimento na ampliação do estoque de capital fixo nos países europeus foi de 4,6\% nos anos 1960 e de $3,8 \%$ nos anos 1970, descendo repetidamente para 2,9\%,2,8\% e 2,6\%, respectivamente, nas décadas de 1980, 1990 e no período entre 2000 e 2004. Nos EUA, estes indicadores também trilharam a mesma trajetória declinante, respectivamente: 4,0\%, 3,8\%, 2,8\%, 3,0\% e 2,0\% (Glyn, 2006, p. 86).
} 
capitalistas ocidentais com a URSS (unidas apenas por causa do inimigo comum - o nazismo), ficava claro que dois sistemas econômicos e políticos seriam protagonistas de uma renhida rivalidade ideológica dali em diante. A preocupação das autoridades econômicas dos países europeus ocidentais (assim como as dos EUA) era evitar que a recuperação econômica soviética (então em notória trajetória exitosa) do imediato pós-segunda guerra pudesse afetar a disputa política dentro desses países. Esta preocupação tornou-as mais comprometidas com a elaboração de políticas macroeconômicas que tivessem como principal objetivo o pleno emprego, uma vez deflagrada e conseguida a reconstrução europeia. Segundo Streeck (2018), no início dos anos 1970, ainda existia um consenso ("convicção generalizada") de que o pleno emprego "constituía a pedra angular do contrato social do capitalismo do pós-guerra" (p. 79).

Diversas maneiras de intervenção estatal foram postas em prática nas sociedades capitalistas para construir esse referido contrato social, como forma não apenas de iniciar a reconstrução das economias devastadas pela guerra, e, a seguir, de dinamizar estas economias, como também de combater a pobreza e enfrentar a desigualdade socioeconômica. Experiências anteriores, como o New Deal americano, serviam de referência para as medidas que seriam tomadas nos mais variados países, cada um com suas peculiaridades. Ainda nos EUA, o experimento da "Guerra à Pobreza" de Lyndon Johnson, nos anos 1960, representou $^{6}$ um desdobramento de algumas medidas que já vinham sendo tomadas desde os anos 1930.

Esse período de prosperidade teria, sobre a literatura econômica, um efeito de provocar uma decrescente preocupação com o tema da desigualdade, seja porque, supostamente, a mesma fosse identificada como um fenômeno estável ao longo do tempo, ou, quando não, a concentração da renda (ampliação da desigualdade) seria interpretada como algo positivo, por estimular investimentos produtivos (e, portanto, supostamente posterior prosperidade econômica e social

\footnotetext{
${ }^{6}$ Obra de Jansson (2009) descreve em detalhes a evolução das políticas públicas que foram adotadas desde a Constituição da nação estadunidense. Através de uma análise minuciosa e abrangente, o autor mostra como se desdobram e se relacionam os determinantes políticos, geopolíticos e sociais (incluindo a escravidão e suas consequências sociais e políticas - com repercussões parlamentares regionalmente definidas) que permitiram a expansão, mas colocaram limites para a criação do Estado de Bem Estar nos EUA. Um dos pontos chaves de sua análise é mostrar que o auge do Welfare State se deu nos anos 1960, mas não deixa de registrar que a consolidação das políticas públicas e dos programas sociais de então estavam invariavelmente influenciados pelos episódios sociais dos tempos do New Deal e, dentro desse contexto, destacava também as contendas raciais como um elemento explicativo central para a compreensão da evolução e da formatação do Welfare State norte americano.
} 
para o conjunto do sistema ${ }^{7}$ ) por parte dos inicialmente beneficiários da própria expansão da desigualdade. Esta postura advinha de uma mentalidade conservadora/conformista que tomou conta da academia durante o período, consolidando-se especialmente ao longo dos anos 1970, que pode ser resumida pelo aforismo de Aaron (1978, p. 2), segundo o qual "watching trends in income inequality is like watching the grass grow", citado em diversos estudos nos anos subsequentes à sua publicação. Comentando sobre a atenuação da importância conferida ao tema no debate econômico do período de prosperidade, John Kenneth Galbraith (1998[1958]), na introdução da versão em inglês do quadragésimo aniversário da publicação de seu livro The Affluent Society, assevera que, passados quarenta anos, sustentava todas as principais conclusões da publicação original, mas pondera que, depois desse período, "I would now, however, more strongly emphasize, and especially as to the United States, the inequality in income and that it is getting worse" (p. viii). Esta reflexão, por parte do autor, ilustra como, no espaço de tempo mencionado, a percepção de piora do perfil distributivo torna-se cada vez mais evidente, tendo merecido tal contrição até mesmo por parte de um arguto pensador americano que havia interpretado de forma tão inovadora o processo de prosperidade econômica vivido pela sociedade americana desde os anos pós-Grande Depressão de $1929^{8}$.

O ressurgimento do debate sobre desigualdade ocorre nos anos 1980, quando restava evidente que aquele período de prosperidade com trajetória de equidade (redução contínua da desigualdade da renda pessoal na maioria dos países desenvolvidos) mostrava esgotamento. James Galbraith (2016a), contextualizando a retomada do interesse no tema, o situa no momento da

\footnotetext{
${ }^{7}$ Esta suposição (que, a rigor, conforme lembra Galbraith $(2009,2019)$, é muito mais uma justificativa para a desigualdade) está por trás dos comentários registrados como epígrafes neste artigo.

8 O trabalho clássico de John K. Galbraith (1998 [1958]) reúne diversos argumentos para apoiar sua avaliação segundo a qual, naqueles tempos de prosperidade, o tema da desigualdade e da distribuição de renda tenha perdido protagonismo nos debates acadêmicos e mesmo políticos. $\mathrm{O}$ autor pondera que, no contexto da "sociedade afluente" do final dos anos 1950, a prosperidade econômica e social, bem como a naturalização da ideia segundo a qual o sucesso dependia do esforço pessoal, o culto ao individualismo e, em poucas palavras, o triunfo do pensamento conservador criaram o ambiente para que a desigualdade deixasse de ser um tema relevante dos estudos econômicos. O autor, para deixar claro seu ponto de vista, pontua que, mesmo os programas que fizeram parte da "Guerra à Pobreza", do governo de Lyndon Johnson, nos anos 1960, não tinham objetivo explícito e nem políticas definidas para combater a desigualdade, mas sim para aliviar a pobreza e, desta forma, atenuar as tensões sociais. Fica implícito, na análise seminal do autor, que o cenário de prosperidade da economia americana no período permitiu que o tema da desigualdade fosse relegado a plano secundário ou mesmo pouco debatido, embora isso não significasse, segundo ele próprio fez questão de salientar, que a desigualdade não permanecesse como um problema grave da sociedade americana.
} 
publicação de livro intitulado The Great U-Turn, de autoria dos economistas Barry Bluestone e Bennett Harrison (1988). Esse interesse, segundo Galbraith (2016a), persistiria até os dias atuais 9 . A "reversão" da curva de Kuznets trouxe à tona uma ampla discussão acerca de suas causas e desdobramentos ${ }^{10}$, estimulando o debate sobre o tema. Do ponto de vista dos conservadores, a consolidação de formulações teóricas com base na Teoria do Capital Humano, que havia sido lançada nos anos 1960, teve papel importante para a retomada do debate sobre desigualdade econômica e distribuição de renda (de um ponto de vista pessoal, e não funcional), conforme chama atenção o estudo de Goldfarb e Leonard (2005). Os autores ponderam que a ascendência da Teoria do Capital Humano, incentivada pelos benefícios interativos da nova teoria, em conjunção com os novos dados colocados em disponibilidade pela atuação de diversas instituições de pesquisa, marcam a conquista neoclássica da chamada Economia do Trabalho (Labor Economics), "one of the last institucionalist redoubts in american economics". Os mercados para pessoas eram, segundo os neoclássicos, como os mercados para os produtos, segundo Goldfarb e Leonard (2005, p. 95).

O fortalecimento da discussão sobre desigualdade nos anos 1980 foi viabilizado pela crescente disponibilidade de dados sobre rendimentos e de ferramentas para o tratamento das informações estatísticas de renda e de riqueza, mas o contexto que animou esse debate se explica pela "surpresa" provocada pela reversão da curva do "U invertido", já evidentes no início da década de 1980. A discussão acerca da natureza das políticas liberais postas em prática por Thatcher e Reagan (que rapidamente adotaram medidas que se diferenciavam claramente do que ocorrera especialmente nos anos 1950 e $1960^{11}$ ) tinha, no tema da

\footnotetext{
9 "Today, few things are more evident in modern social history than the revival of interest in inequality." (Galbraith, 2016a, p. 71).

10 São diversas as interpretações acerca dos motivos para esta "virada" ocorrida nas economias desenvolvidas, entre um momento de prosperidade e redução de desigualdade e outro, de menor prosperidade (especialmente na Europa) e ampliação da desigualdade. Não está no escopo deste artigo recuperar essas discussões, mas o cerne das alterações dos respectivos padrões de acumulação e perfil do crescimento reside nas mudanças ocorridas na Ordem Financeira Internacional (OFI), conforme mostram, pelo menos, os trabalhos de Belluzzo (1995, 2016), Galbraith (2002, 2009, 2012, 2016a, 2016b, 2018), Mattos (2009), Palma (2006, 2009), Reich (2017), Streeck (2018) e Dedecca (2012a, 2012b).

${ }^{11} \mathrm{Na}$ verdade, as contradições do sistema financeiro internacional centrado no dólar já vinham de antes, e as primeiras medidas que romperam os acordos de Bretton Woods também antecederam as eleições de Thatcher e Reagan. O abandono unilateral, em agosto de 1971 (por Nixon), por parte dos EUA, do compromisso firmado em Bretton Woods (na Conferência que estabelecera as regras de funcionamento do sistema financeiro internacional) de respeitar a paridade do dólar com o ouro e de honrar a conversibilidade de sua moeda no referido metal (garantindo os valores, em ouro, das reservas em dólar mantidas pelos demais países), marcou o início de derrocada dos acordos cambiais do pós-segunda guerra, com efeitos negativos sobre a estabilidade do sistema financeiro internacional, comprometendo a capacidade de os
} 
desigualdade, um de seus aspectos mais importantes (pelo menos entre pesquisadores de linhagem heterodoxa). A retomada da discussão sobre a desigualdade a partir dos anos 1980 também pode ser explicada por aspectos relacionados às reminiscências dos então ainda recentes Anos Dourados e a consequente percepção social, segundo Atkinson (1997), de que a mudança do perfil da distribuição pessoal da renda representava uma deterioração das condições de vida das populações. Portanto, o aumento sistêmico da desigualdade econômica nas sociedades capitalistas ocidentais concorria decisivamente para que o tema da desigualdade na distribuição de renda fosse redivivo. Esta discussão, até o final dos anos 1990, restringiu-se à organização de dados relacionados às rendas pessoais do trabalho apropriadas pelos extratos populacionais. Nas décadas seguintes, as formas de apuração dos dados e o advento de técnicas para seu tratamento colocariam o debate em termos mais amplos e mais conclusivos, ao mesmo tempo em que permitiriam o alargamento do debate sobre desigualdade para um aspecto multidimensional típico de interpretações estruturalistas.

É notório que, a partir dos anos 2000, novas evidências de aumento da desigualdade de renda, bem como a percepção de uma mudança na natureza do perfil dos rendimentos (segundo suas diversas fontes e segundo a intensidade desigual com que os ganhos de renda passam a ser apropriados pelos diferentes estratos da pirâmide distributiva) abriram maneiras adicionais de abordar a questão da desigualdade, destacando que o entendimento da mesma demandaria a necessidade de trazer para debate não apenas fatores econômicos, mas também políticos, sociais e institucionais que se mostravam cada vez mais reconhecidos como elementos que também concorriam para a sua trajetória ${ }^{12}$. Esse debate, de

Estados Nacionais manterem os aspectos centrais que haviam permitido a adoção de políticas macroeconômicas de pleno emprego ao longo dos anos 1950 e 1960. Em outubro de 1979 (últimos meses do governo Carter), o gesto de Paul Volcker, então presidente do FED, de aumentar, de maneira unilateral e abrupta, as taxas de juros do mercado americano, promoveu o golpe fatal na ordem financeira que havia sido concertada no pós-segunda guerra. Em contexto de já elevada expansão dos fluxos financeiros internacionais, este gesto tornou o ambiente financeiro internacional ainda mais instável, provocando uma crise sistêmica que, segundo diversos autores, perdura, de variadas formas, até hoje. Para detalhes de como as acima referidas medidas promoveram o rompimento da ordem financeira internacional construída em Bretton Woods, ver Belluzzo (1995). Para detalhes dos bastidores das referidas medidas (1971 e 1979), recomenda-se Moffitt (1984).

${ }^{12}$ Esta forma mais abrangente (ou, em outros termos, estruturalistas) de discutir a questão da desigualdade, quer seja em sua forma econômica, ou nas suas manifestações sociais, mereceram uma reflexão consistente por parte de Dedecca (2012a), que mostra que, nos anos 2000, os organismos internacionais se debruçam nova e crescentemente no tema da desigualdade, revelando diferentes (mas complementares) esforços para abordar a questão. O autor menciona os trabalhos de UN (2005), ILO (2007) e OECD (2008). O estudo da OIT (Organização Internacional do Trabalho, ou ILO, na abreviação em inglês), discute a expansão da desigualdade proveniente da evolução dos rendimentos definidos nos mercados de trabalho. $\mathrm{O}$ trabalho da 
caráter mais abrangente do que o que animou o dos anos 1980 e 1990, pode ser sintetizado no que chamaremos aqui de "o debate do 1\%”, tema da próxima seção.

\section{A questão do $1 \%$ do topo e seus desdobramentos}

A partir dos anos 2000, a questão da renda apropriada pelo $1 \%$ de maiores rendas das respectivas populações dos países desenvolvidos se torna cada vez mais presente nas pesquisas sobre desigualdade. Tal fato se deve, inicialmente, à constatação de que este estrato da população vinha amealhando parcelas crescentes da renda criada pelas economias capitalistas desenvolvidas. A expansão dos estudos sobre o tema se debruçou também na necessidade urgente de se discutir novos aspectos metodológicos para compreender e tratar os dados que diversos institutos ou grupos de pesquisa, em importantes universidades norte-americanas ou europeias, vinham coletando e organizando. Esta questão metodológica ajudou a interpretar a composição, a natureza e a origem dessas altas rendas, o que, por sua vez, consolidou a percepção de que era importante incorporar aspectos político/institucionais para compreender a complexidade do fenômeno da "hiperconcentração de renda".

No início dos anos 2000, Jencks (2002) já alertava para a dimensão da concentração, mostrando que, entre 1979 e 1997, o poder de compra do $1 \%$ do topo da distribuição havia crescido, em termos reais, $157 \%$, enquanto a renda domiciliar mediana havia se ampliado em apenas $10 \%$ no mesmo período. Resultados de dois períodos recentes de prosperidade na economia dos EUA ilustram, de forma ainda mais explícita, a extrema e crescente desigualdade, expressa pela apropriação, por parte do "1\% do topo", de parcelas significativas da renda criada em cada período - revelando o caráter crescentemente concentrador da renda nos tempos recentes. Na mesma linha, dados mencionados por Piketty e Saez (2013) mostraram que, entre 1993 e 2000 (período de expansão econômica do período Clinton, que foi de $4,0 \%$ de crescimento real do PIB ao ano, em média), o $1 \%$ mais rico dos EUA absorveu cerca de $45 \%$ do total de

OCDE (OECD, na versão em inglês) analisa a evolução da desigualdade a partir de dados de renda disponível, ou seja, levando em conta os rendimentos auferidos nos mercados de trabalho, mas corrigidos pelos impostos e transferências, ou seja, levando em conta a política tributária e as políticas sociais formatadas pelos respectivos sistemas nacionais de Estado de Bem Estar Social. Já o estudo das Nações Unidas (UM - United Nations, na versão em inglês) propõe uma análise mais ampla, incorporando dimensões não associadas apenas à renda e à posse de riquezas para avaliar o fenômeno da desigualdade. De todo modo, a abrangência e regularidade dos estudos revela o rejuvenescido e ampliado interesse pelo tema - bem como a necessidade de discuti-lo de uma forma multidimensional (Dedecca, 2012a). 
crescimento da renda do país. Esta parcela já elevada aumentaria para $65 \%$ entre 2002 e 2007, período em que o crescimento foi menor (3,0\% ao ano, em média, na expansão do governo Bush Filho). Há ainda indicações de que, após a crise deflagrada pela derrocada dos créditos de subprime (em setembro de 2008), a participação do $1 \%$ na renda total da economia americana (e em muitos outros países também) continuou a subir ${ }^{13}$.

Esta contínua expansão da parcela da renda apropriada pelo topo percentil do topo da distribuição (" $1 \%$ mais rico") trouxe para a discussão aspectos políticos e institucionais que, uma vez analisados, têm iluminado o debate sobre a desigualdade, tornando-o mais abrangente e elucidativo para interpretar as causas da trajetória recente dos indicadores estatísticos sintéticos ${ }^{14}$ da desigualdade econômica - e para compreender a crescente deterioração do perfil distributivo. A contribuição de pesquisadores sobre a questão da desigualdade, reunindo dados, construindo séries históricas longas e discutindo metodologias para a compreensão da composição das rendas do topo, tem sido fundamental para destacar a necessidade de se ampliar a discussão para além da compreensão e descrição da trajetória das rendas do trabalho ${ }^{15}$. As rendas do capital, em diferentes intensidades e origens ${ }^{16}$, passam a compor, de uma forma cada vez mais diversificada (e

13 Dados divulgados pelo site Inequality.org (organizados pelo economista Emmanuel Saez, da Universidade de Berkeley, com base em informações oficiais do Censo dos EUA) mostram, por exemplo, que, em 2009, o primeiro percentil acumulava $18 \%$ da renda nacional dos EUA, parcela que saltou para $19 \%$ em 2010 e 2011, atingindo $23 \%$ em 2012, e retrocedendo para 21\% em 2017 (de todo modo, ainda bem acima do percentual de antes da crise do subprime). Esta elevada concentração continuou a se elevar mesmo depois de ter sofrido duas fortes altas, como a ocorrida entre 1980 e 1994 (de 10\% para 14\% do total da renda nacional) e aquela que aconteceu entre 1994 e 2000 (salto de $14 \%$ para 22\%). Nas subdivisões ainda menores dentro do estrato do $1 \%(0,1 \%$ e $0,01 \%)$, a escalada de iniquidades tem sido ainda mais intensa. Para mais detalhes, ver link: https://inequality.org/facts/income-inequality/ Acesso em 04 de agosto de 2019. Com relação a dados referentes a outros países, organizados de forma semelhante, pode-se constatar que também entre 1980 e os anos 2000 a apropriação das respectivas rendas nacionais pelo topo $1 \%$ aumentou expressivamente; da mesma forma, continuou aumentando ao longo dos anos 2000 e não houve reversão desses movimentos ascensionais nem mesmo após a deflagração da crise do subprime de setembro de 2008. Os dados do site Our World In Data mostram isso cabalmente: Ver https://ourworldindata.org/income-inequality Acesso em 04 de agosto de 2019.

${ }^{14}$ Como, por exemplo, os Índices de Gini e de Theil, ou as parcelas da renda nacional apropriadas pelos diferentes extratos populacionais, quer sejam eles separados em faixas de $10 \%$ (os decis), ou faixas maiores, como, por exemplo, os percentis, como no caso do próprio debate sobre o " $1 \%$ mais rico".

${ }^{15}$ Estudos de desigualdade econômica que tenham como referências as rendas provenientes do trabalho são os mais encontradiços na literatura econômica - e sem dúvida ainda têm a sua importância. A questão é que, nas últimas décadas, muitos estudos e vários autores alertam que a interpretação da evolução da desigualdade econômica apenas levando em conta este ponto de vista limita as possibilidades de entendimento do fenômeno e de seus efeitos sociais, bem como econômicos (como a discussão de como a desigualdade afeta o próprio dinamismo da economia, por exemplo).

${ }^{16}$ Quer sejam as rendas provenientes do capital produtivo (em diferentes atividades econômicas), ou as rendas oriundas do capital financeiros (da mesma maneira, em suas diferentes modalidades, expressas em uma ampla miríade de estoques de ativos que, por sua vez, geram fluxos de rendimentos em favor de seus 
crescentemente significativa), a renda dos estratos populacionais mais elevados ( $1 \%$ ou suas subdivisões ainda menores $)^{17}$.

A compreensão da evolução desses rendimentos e de seu perfil tem exigido um esforço interpretativo acerca da forma de funcionamento das instituições que regem as sociedades e as formas pelas quais estas atuam na regulação das diferentes maneiras de geração de renda, da cobrança de impostos e da regulação da concorrência em diferentes mercados. Nesse sentido, Wade (2005) chama a atenção para a importância de estudos sobre a desigualdade para compreender como funcionam as sociedades modernas, bem como quais as consequências sociais decorrentes das formas como fatores político/institucionais afetam o perfil distributivo. $\mathrm{O}$ autor alerta que existe um certo consenso segundo o qual em sociedades muito desiguais também são elevados os índices de criminalidade, de pobreza, de indicadores de saúde (e bem estar), de desemprego e de diferente acesso a serviços públicos, bem como da participação em fóruns de tomada de decisão sobre o funcionamento do Estado. O autor pontua que "societies with higher degrees of income inequality have societal institutions whose rules and resource allocations are more skewed in favor of the rich (because framed by the rich)" (Wade, 2005, p. 28-29). Ou seja, Wade (2005), tanto neste como em outros trabalhos (Wade, 2004, 2011, 2014), alerta que o fenômeno da desigualdade, tanto em sua esfera econômica quanto na social ${ }^{18}$, não responde apenas às "forças de mercado" atuando na atividade econômica. Em primeiro lugar, porque estas "forças" dependem de regulação estatal, mas também porque a geração e provisão de rendas secundárias depende de fatores político/institucionais que se auto reforçam com fatores econômicos geradores das rendas primárias ${ }^{19}$ na conformação de perfis distributivos cada vez mais desiguais.

\footnotetext{
detentores), para não esquecer, ainda, os rendimentos do capital imobiliário tradicional ("real estate assets") e tampouco de diferentes formas de exploração de patentes ou outros direitos de propriedade que surgem na esteira do desenvolvimento e exploração das novas tecnologias (a exploração desses direitos, por sua vez, também depende das formas de regulação propostas pelos Estados Nacionais, e das dificuldades crescentes para evitar que essas tecnologias não promovam novas modalidades de desigualdade social e econômica - conforme denuncia o excelente livro de Eubanks (2017)).

${ }^{17} \mathrm{Na}$ verdade, de acordo com o que mostra Piketty (2014), a composição das rendas de subdivisões menores do estrato do $1 \%$ do topo mostra maior participação de rendas provenientes do capital. Ou seja, à medida que se "caminha" para o topo da distribuição, aumenta a presença de rendas provenientes de diversas modalidades do capital.

18 Autores de formações tão diversas, como os economistas Joseph Stiglitz (de formação neoclássica) ou Robert Reich (keynesiano), ou o sociólogo marxista Göran Thernborn também apontam aspectos sociais disruptivos e efeitos negativos sobre diversas dimensões da vida social promovidos pela ascensão recente da desigualdade.

${ }^{19}$ Rendas criadas no âmbito do mercado de trabalho.
} 
Nos anos 1990, artigo premonitório de Atkinson (1997) já destacava não somente a expansão da desigualdade ocorrida a partir dos anos 1980, como também a presença de fatores políticos e institucionais na explicação para esse fenômeno. A questão tributária e o desenho das políticas públicas ficam claras na seguinte passagem, em que o autor contextualiza a crescente presença de rendas de outras fontes que não o trabalho nos orçamentos familiares: "The main source of income for those not in work is in fact social security, and this brings me to the distributional impact of the government" (1997, p. 306). A seguir, tratando das diferenças entre os indicadores sintéticos de desigualdade (medidos pelo índice de Gini) medidos levando em consideração as rendas de mercado ("private income", ou pre-tax) e os que levam em conta as rendas calculadas após a incidência de impostos e transferências (post-tax), ele destaca:

We cannot draw any conclusions from this difference as to the actual
incidence of the government budget, but it is, nonetheless, interesting
that the Economic Trends study shows that in the first half of the 1980s
the Gini coefficient for private income (not including transfers)
increased sharply, with a much more moderate increase in the
coefficient for the post-tax and benefit income. At first sight, at least,
the welfare state appears to have moderate the rise in pre-transfer
incomes. After 1984 the situation reverses: the Gini coefficient for
original incomes rose by one percentage point form 1984 and 1989 but
that for post-tax income increased by seven percentage points
(Atkinson, 1997, p. 306).

Ou seja, o autor já estava percebendo e pontuando que o efeito corretivo da política fiscal, a partir dos anos 1980, estava perdendo força, contrastando com o que ocorrera nas décadas anteriores.

Na mesma linha, Piketty (2014) chama a atenção para a generalização de práticas de isenções tributárias quando registra suas explicações a respeito da natureza e perfil dos rendimentos do topo nas economias capitalistas (com maior ênfase nos EUA). Segundo o autor, o aumento da parcela que o $1 \%$ mais rico absorve da renda nacional deve-se tanto à expansão dos supersalários do CEOs das grandes empresas produtivas e financeiras como também dos rendimentos do capital, destacando que, em ambos os casos, as leis tributárias demonstraram ter tido papel decisivo.

Galbraith (2016a) se soma a Piketty (2014), lembrando que a expansão dos altos salários dos executivos deveu-se a mudanças na tributação e à desregulação das normas de determinação dos salários dos mesmos (ambos fatores relacionados 
a mudanças feitas na legislação dos respectivos países), bem como a novas condutas adotadas também no âmbito das transformações das estratégias empresariais (Streeck, 2018) nesses anos do "capitalismo desregulado". Estes novos procedimentos envolvem tanto as decisões de reorganizar a produção como também as de organizar as estruturas administrativas das empresas (Dedecca, 2012b).

Estes fatores relacionados a estratégias do âmbito empresarial não escapam à análise dos autores mencionados nesta seção. O que merece registro é o fato de que todos eles procuram destacar que são os aspectos macroeconômicos (e não a microeconomia dos estudos neoclássicos da Economia do Trabalho) os fatores dominantes na explicação da crescente desigualdade, notadamente pelo fato de que as transformações na ordem internacional condicionam os limites para a execução da política (macro)econômica e, por esta via, afetam os aspectos relacionados à organização das plantas produtivas. Sobre a importância de se ampliar o leque de interpretação acerca do processo de crescente desigualdade, as palavras de Atkinson (1997) espetam as questões centrais, ressaltando os novos desafios para a Teoria Econômica:

My principal purpose here has been to argue that the economic analysis of the distribution of income is in need of further development before we can hope to give a definitive answer to the questions in which the ordinary person is interested - such as what determines the extent of inequality and why has inequality increased? This does not mean that current economic theory has nothing to contribute. It certainly offers insights into parts of the story, but what is required is for the different elements to be brought together. We need an overall framework, both conceptual and empirical, within which to fit the different mechanisms. The skill shift explanation for wage differentials is valuable, but it is only part of the story. The labour market cannot be seen as totally independent from the capital market. Both economic and political economy explanations have their place (Atkinson, 1997, p. 317).

Também a expansão das rendas financeiras a taxas maiores que os rendimentos provenientes da esfera produtiva (Piketty, 2014) resultam das características das políticas econômicas adotadas pelos países a partir de 1980, o que inclui os aspectos político/institucionais que vimos. A expansão da presença dos rendimentos do capital nos extratos mais altos de renda decorre, conforme já mencionamos, das novas formas de organização da produção, mas também do cenário de enfraquecimento dos sindicatos e da própria deterioração dos mercados de trabalho, conforme devemos discutir na próxima seção. Dentro deste contexto, tem importante papel a crescente "financeirização da riqueza" e seus efeitos nas 
decisões de investir (ou não) na produção, com evidentes impactos sobre a geração de empregos e sobre o mundo do trabalho como um todo (também tema da próxima seção). Por ora, vale lembrar que os trabalhos pioneiros de François Chesnais, nos anos 1990, já chamavam a atenção para os efeitos das "formas predominantemente financeiras" de acumulação capitalista (Chesnais, 1996a, 1996b, 1997, e, também, mais recentemente, em Chesnais, 2002) sobre as atividades do setor produtivo.

Os dados organizados por Keister (tabela 1) ilustram a crescente financeirização da renda a partir de uma análise do perfil da renda e da riqueza nos orçamentos familiares - outra forma de ilustrar o processo de financeirização. As informações referem-se à realidade dos EUA, mas podem ser definidos como um retrato do padrão de acumulação que se instala a partir dos anos $2000 \mathrm{em}$ todos os países capitalistas, guardadas diferentes intensidades (Epstein, 2005).

Tabela 1 - Evolução recente do perfil da renda e da riqueza (financeira e não-financeira) em percentuais apropriados por cada estrato em cada caso famílias dos EUA nos anos 2000

\begin{tabular}{c|ccc|ccc|ccc}
\hline \multirow{2}{*}{$\begin{array}{c}\text { Anos e } \\
\text { estratos }\end{array}$} & \multicolumn{3}{|c|}{ Renda } & \multicolumn{3}{c|}{ Riqueza líquida } & \multicolumn{3}{c}{ Ativos financeiros } \\
\cline { 2 - 10 } & top & $\mathbf{n e x t}$ & $\mathbf{n e x t}$ & $\mathbf{t o p}$ & $\mathbf{n e x t}$ & $\mathbf{n e x t}$ & top & $\mathbf{n e x t}$ & $\mathbf{n e x t}$ \\
& $\mathbf{1 \%}$ & $\mathbf{9 \%}$ & $\mathbf{9 0 \%}$ & $\mathbf{1 \%}$ & $\mathbf{9 \%}$ & $\mathbf{9 0 \%}$ & $\mathbf{1 \%}$ & $\mathbf{9 \%}$ & $\mathbf{9 0 \%}$ \\
\hline 2001 & 19,7 & 25,4 & 54,9 & 32,3 & 37,4 & 30,4 & 36,4 & 38,8 & 24,9 \\
2004 & 17,0 & 25,6 & 57,4 & 33,2 & 36,2 & 30,6 & 36,6 & 39,1 & 24,3 \\
2007 & 21,3 & 25,8 & 52,9 & 33,6 & 37,8 & 28,6 & 37,6 & 39,2 & 23,2 \\
2010 & 17,2 & 27,2 & 55,6 & 34,1 & 40,3 & 25,6 & 35,6 & 43,6 & 20,8 \\
\hline
\end{tabular}

Fonte: elaboração de Keister (2014), com base em dados de Surveys of Consumer Finances.

O já mencionado estudo de Atkinson (1997), além de destacar o papel que a mudança do perfil distributivo teve sobre as condições de vida das populações dos países desenvolvidos, também chama atenção - dada a magnitude da escalada da concentração e de seu perfil - para o fato de que a queda da participação da renda do trabalho no conjunto da renda das famílias abria novos flancos de avaliação necessários para compreender o fenômeno recente da desigualdade econômica. Atkinson (1997) apontava para a necessidade de ampliar a interpretação sobre a evolução da distribuição pessoal da renda para além das rendas do trabalho. E de fato, nas décadas seguintes, proliferaram estudos devotados a estudar as rendas provenientes do capital concomitantemente às rendas provenientes das políticas sociais, estas fortemente afetadas pela dinâmica 
da política e da democracia no período (Galbraith, 2018; Palma, 2009; Hacker; Pierson, 2010).

A discussão sobre a natureza do padrão de acumulação capitalista dos anos 2000, na esteira da instalação e intensificação do debate sobre o $1 \%$, inclui em sua agenda a temática do rentismo. O rentismo é mais do que meramente um fenômeno econômico. Inclui aspectos institucionais e políticos que se unem para formatar os modos de reprodução do "capital fictício" (Belluzzo, 2016; Marx (1968 [1867])) e, ao mesmo tempo, também para influenciar na elaboração da legislação e da regulação de mercados, de forma a defender, ampliar e reproduzir as rendas do topo. A definição do conceito de "income defense industry", por parte de Winters (2011), define aspectos importantes que relacionam as relações políticas moldadas dentro da atual ordem democrática e os negócios do setor privado - e sintetizam os argumentos adiantados por Atkinson (1997). Vale citar as seguintes passagens do autor:

Since ancient times, taxation has always been a central and conflictual matter in political economy. Tax rates and burdens are a direct reflection of power. Although discussions can be mind-numbing, who pays taxes and how much they pay is linked to important notions of justice, fairness, morality, legitimacy, and citizenship (Winters, 2011, p. 212).

E também:

Both as service providers and as political agents, the Income Defense Industry exists only because of the substantial material threats oligarchs face and the material power they exercise to counter them. This argument specifies the interests oligarchs have and traces the mechanisms through which power is used - and political outcomes are achieved - to address those interests (Winters, 2011, p. 214).

Desta forma, fica claro como, sob a ordem capitalista atual, os conflitos de classes e os interesses específicos de grupos econômicos e financeiros vão se transladando para disputas em torno da elaboração dos orçamentos públicos; da mesma forma, a democracia contemporânea encaminha decisões sobre todas as formas de regulação pública ${ }^{20}$ que, em outros momentos, tiveram efeitos positivos

\footnotetext{
${ }^{20}$ Entre elas, se destacam várias, como por exemplo as formas de regulação do trabalho, a atividade da Justiça trabalhista, ou da Justiça em geral, nos países onde não há uma forma específica de Justiça dedicada a questões do trabalho; a regulação e normas de acesso aos benefícios do seguro-desemprego; as regras da previdência social, notadamente no que afeta ao funcionamento do mercado de trabalho e à geração de renda e seu impacto sobre o dinamismo da própria economia; a relação entre as políticas educacionais e o
} 
(do ponto de vista do trabalho, mas também do ponto de vista de grupos capitalistas que visavam aos mercados internos dos países) em termos de uma mais equânime distribuição dos excedentes produtivos criados nas atividades manufatureiras e em outras atividades produtivas (Mattos, 2019).

Essa temática da convivência da democracia com novas e ampliadas formas de concentração da renda e da riqueza tem atraído diversos estudos de cientistas políticos que também procuram entender o comportamento e a trajetória da desigualdade socioeconômica nos tempos recentes. Estudo abrangente e detalhado conduzido por Bonica et al. (2013), tratando do funcionamento da democracia e do processo eleitoral nos EUA, e seus efeitos sobre a regulação da economia e sobre a desigualdade socioeconômica, sintetiza os mais importantes aspectos de que se reveste o tema. Os principais argumentos dos autores repousam nos seguintes aspectos: (a) crescente hegemonia do pensamento conservador, de tal forma que tanto republicanos como democratas tendem a se diferenciar pouco em relação às pautas econômicas; (b) no processo legislativo, predominam as medidas de desregulamentação dos mercados de trabalho e financeiros; (c) no executivo, as políticas econômicas dos últimos anos adotaram práticas fiscais regressivas e que esvaziaram programas sociais, de tal forma que desidrataram o papel que as políticas redistributivas haviam exercido na sociedade americana nas décadas do pós-segunda guerra; (d) acusam os democratas de concentrar esforços em pautas identitárias, ao invés de devotar atenção a medidas econômicas que pudessem subverter a crescente desigualdade social; (e) o cenário de ampliação das diversas modalidades de desigualdades, ao contrário do que poderiam prever os postulados do "eleitor médio" demandando "correção" dessas iniquidades, provoca, na verdade, desilusão com a política e forte polarização do debate parlamentar, interditando uma discussão mais racional acerca do funcionamento da economia nos tempos atuais; (f) a desilusão com a política é comprovadamente maior entre os mais pobres, que revelam menor participação no processo eleitoral e menos presença nas urnas; (g) essa menor participação dos pobres, por sua vez, distorce a representatividade política, pois, na prática, tende a ampliar a bancada de parlamentares que dedicam seus mandatos a favorecer os interesses de grandes grupos econômicos - que financiam as campanhas e pressionam os parlamentares;

mercado de trabalho (notadamente no que se refere às políticas de formação profissional) etc. Para mais detalhes acerca destas formas de regulação, ver Dedecca (2010, 2012b). 
(h) a própria expansão da desigualdade torna os menos favorecidos mais apáticos (contrariando a tese do "eleitor médio", conforme já afirmamos) em relação à participação política e céticos quanto ao papel que a democracia pode(ria) desempenhar para corrigir as distorções econômicas, reforçando o círculo vicioso conduzido pelo sodalício "concentração do poder e da riqueza"; (i) por fim, mas não menos importante, os autores tratam de aspectos institucionais específicos do sistema eleitoral americano, mostrando que o voto distrital (e os critérios ad hoc para desenhar os distritos) distorce a proporcionalidade dos partidos, debilita a representatividade e, no limite, amplia as desigualdades econômicas.

A leitura de Streeck (2018), retratando aspectos do funcionamento da democracia nos principais países europeus revela que, em linhas gerais, as questões elencadas pelo estudo de Bonica et al. (2013) valem também para os países do Velho Continente, nomeadamente a precarização do trabalho, de tal forma que, lá também, os resultados econômicos regressivos ampliam a desilusão com a política e abrem caminho, notadamente nos momentos de recessão ou de crise econômica sistêmica, para a adoção de novas medidas que, na prática (embora não nas “promessas" e justificativas pretéritas), ampliam as desigualdades já existentes. Desta forma, os estudos mencionados revelam como a concentração do poder político se coaduna com a concentração da renda e da riqueza, através da manipulação das instituições democráticas em favor dos mais ricos.

Para completar os objetivos do artigo, deve-se agora destacar como a compreensão do fenômeno da desigualdade em ascensão ajuda a explicar a natureza das transformações do mundo do trabalho.

\section{Como o estudo da desigualdade ajuda a compreender as mudanças no mundo do trabalho}

Tendo como referência a contextualização histórica da trajetória dos indicadores de desigualdade do pós-segunda guerra e as mudanças estruturais ocorridas no padrão de acumulação (sintetizadas pela natureza do "debate sobre o 1\% mais rico"), devemos, nesta seção, buscar destacar a importância da compreensão da evolução da desigualdade econômica para entender as transformações ocorridas no mundo do trabalho.

A transição entre a economia regulada das décadas de ouro do capitalismo e o momento a partir do qual o cenário econômico internacional passa a ser hostil à 
ação reguladora dos Estados Nacionais e, portanto, também à formatação de políticas públicas que corrigissem ou atenuassem as desigualdades geradas na determinação da renda primária, deve-se fundamentalmente ao fato de que os fluxos financeiros passaram a ser desregulamentados e a instabilidade financeira internacional tornou-se nefasta para a elaboração das políticas macroeconômicas. Os efeitos destas transformações sobre os níveis de desigualdade interna dos países são evidentes. As transformações ocorridas na passagem de uma ordem internacional a outra estão bem resumidas na seguinte passagem de Dedecca (2010):

O desenvolvimento do capitalismo ao longo desse período esteve associado a transformações substantivas na dinâmica e na regulação das relações produtivas e sociais, tendo como referência básica as mudanças no mercado e nas relações de trabalho. O processo de financeirização exacerbada da economia capitalista estabeleceu-se com base em um processo recorrente de desvalorização do trabalho, com uma progressiva precarização das condições de emprego e remuneração, de um lado, e do desemprego, de outro. Como consequência, enfraqueceu-se a institucionalidade da sociedade salarial construída durante as décadas de 1950 e 1960, corroendo a base de sustentação do modelo de política social. Por outro lado, a deterioração do mercado e das relações de trabalho, bem como da política social, alimentaram um retrocesso na distribuição social do excedente produtivo, traduzido no aumento generalizado da desigualdade econômica e social nas nações desenvolvidas e em desenvolvimento (Dedecca, 2010, p. 1-2).

Da mesma forma, a respeito dos limites gerados pelo rentismo para a execução da política econômica e de seu impacto sobre a atividade produtiva e sobre a determinação dos fluxos de renda, já nos anos 1990, Chesnais (1996a) alertava:

É na produção que se cria a riqueza, a partir da combinação social de formas de trabalho humano, de diferentes qualificações. Mas é a esfera financeira que comanda, cada vez mais, a repartição e a destinação social dessa riqueza. Um dos fenômenos mais marcantes dos últimos 15 anos tem sido a dinâmica específica da esfera financeira e seu crescimento, em ritmos qualitativamente superiores aos dos índices de crescimento do investimento, ou do PIB (inclusive nos países da OCDE), ou do comércio exterior (Chesnais, 1996a, p. 244).

Nesta mesma direção, Belluzzo (1996) cunhou a expressão “despotismo dos estoques" 21 para problematizar a questão das decisões de investir sob a ordem

\footnotetext{
${ }^{21} \mathrm{Na}$ expressão cunhada por Belluzzo (1996), o "despotismo dos estoques" significa que a riqueza previamente acumulada (notadamente a que se encontra na forma financeira) torna-se um empecilho para a geração de nova riqueza na esfera produtiva, pois renuncia à rentabilidade garantida e elevada proporcionada pelos ativos financeiros não se revela uma atitude usual, diante da comparação com a rentabilidade que poderiam fornecer as atividades produtivas. Como um subproduto desse cenário
} 
econômica internacional financeirizada ${ }^{22}$. A elevada liquidez e rentabilidade dos ativos financeiros, bem como a segurança de que gozam muitos deles ${ }^{23}$, tornam cada vez mais seletivas e adiadas as decisões de renunciar à liquidez em favor de uma aplicação do capital na produção, com reflexos imediatos sobre a geração de postos de trabalho - e não somente nas atividades industriais. Muitas vezes, a postura mais rentável (e racional) é mesmo a de se apegar aos estoques de riqueza (financeira) já existentes, do que arriscar-se na esfera da produção e da circulação dos produtos.

Essa lógica que determina o comportamento dos agentes econômicos explica o motivo de o crescimento dos PIBs dos países centrais ter sido menor, nos anos 1980 em diante (até os tempos atuais), do que havia sido durante os Anos de Ouro do Capitalismo (Glyn, 2006). A contribuição do professor Chesnais, bem como o mencionado termo cunhado por Belluzzo ${ }^{24}$, ilustram a relação de conflito entre a financeirização da riqueza, de um lado, e a geração de postos de trabalho e de condições para a melhoria dos perfis distributivos, na outra ponta.

$\mathrm{O}$ cenário de crescimento generalizado ${ }^{25}$ da desigualdade de renda e de riqueza, em contexto de concomitância de flexibilização dos mercados financeiros e de desregulação das relações de trabalho, levou Galbraith (2009), com base em estudos comparativos pertencentes a um amplo painel de diferentes regiões em diversos países, a postular que medidas de desigualdade poderiam servir como proxy de "flexibilidade de mercado de trabalho". Nesta formulação, o autor revela que, comparando movimentos de regulação das relações de trabalho em diferentes países

econômico-financeiro-institucional e da postura tomada pelos agentes econômicos, a ampliação da capacidade produtiva de conglomerados empresariais muitas vezes (e cada vez mais, a partir daqueles anos 1990) se apoia em negócios envolvendo fusões e aquisições de ativos já existentes. A ampliação da capacidade produtiva das economias (e, portanto, da geração de empregos), dessa forma, se mostra refém das novas e diversificadas modalidades de valorização financeira do capital.

${ }^{22} \mathrm{Na}$ mesma linha, Wade (2014) destaca o papel disruptivo da ascensão das finanças como fator mais destacado sob o atual padrão de acumulação capitalista: “(...) the huge returns to financial operations distort business incentives, channelling investment away from productive uses into redistributive uses such as mergers and acquisitions, private equity funds, property and financial engineering, which focus more on transfers of ownership of existing assets rather than creation of new ones" (Wade, 2014, p. 116).

${ }^{23}$ Basta lembrar, por exemplo, que, mesmo em cenários de elevada instabilidade financeira internacional (ou, principalmente por isso...), os títulos do Tesouro Americano representam uma garantida "fuga para a qualidade" por parte dos detentores de riqueza do mundo inteiro, conforme já alertavam diversos autores nos anos 1980 e ainda hoje, como na passagem de Galbraith (2018): "even when a financial crisis originates in the United States, as happenned with the subprime-mortgage debacle of 2007-09, funds still flow to the safety of the US dollar and government bonds" (p. 2).

24 "Despotismo dos estoques".

${ }^{25}$ Em vários países do mundo e, dentro de cada um deles, segundo diferentes aspectos, destacando-se a queda da participação salarial na renda e a ampliação, especialmente, dos rendimentos do topo do $1 \%$ mais rico e de suas subdivisões menores $(0,5 \% ; 0,1 \%$ etc. $)$. 
e avaliando a evolução do desemprego neles ao longo dos anos, pode-se perceber uma relação positiva entre desigualdade e desemprego ("more inequality is associated with more, not less, unemployment") ${ }^{26}$. Desta forma, Galbraith (2009) postula que o senso comum do pensamento econômico se mostrou equivocado ao defender que a flexibilização dos mercados de trabalho levaria à geração de mais empregos, conforme mostrou a experiência europeia. Por fim, Galbraith (2009) alertava que, já nos anos 1990, foi possível constatar situações em que a desigualdade de rendimentos crescia enquanto a desigualdade de salário diminuía, em vários momentos e países. Desta forma, o autor desde então chamava atenção para o fato de que os rendimentos do capital já começavam a representar uma contribuição decisiva para o nível de desigualdade de renda nas economias desenvolvidas, conforme mostrariam, nos anos seguintes, as bases de dados que captavam os indicadores de rendimentos da parte superior da pirâmide distributiva (1\% mais rico e subdivisões menores). Este cenário, recorrente nas economias nacionais, decorria, segundo o autor, das mudanças ocorridas na ordem financeira internacional que havia sido construída em Bretton Woods e de seus desdobramentos nas décadas seguintes, conforme pontifica o autor na seguinte passagem, tratando dos movimentos mais gerais da desigualdade de renda nos países:

There are two turning points: from stability to declining inequality around 1973, and from declining to sharply rising inequality around 1982, with the latter pattern persisting until the ending of the millennium. The timing and the world-spanning character of these shifts strongly point to the contemporaneous changes in the global financial regime as bearing responsibility: specifically as the destruction of Bretton Woods in unleashing the commodities/debt boom of the 1970s, and at the rise of global monetarism in 1979-1981 in unleashing the debt crisis and the new era of high real interest rates, which reverberated around the world until 2001. Thus the data, quite free of any a priori or theoretical considerations, point toward the existence of a unified global economy and of powerful macroeconomic forces affecting many countries simultaneously (Galbraith, 2009, p. 201-202).

A desigualdade que se altera, no contexto da mudança da ordem global, é justamente a de poder político e, portanto, de poder de barganha entre as classes sociais. As transformações na forma de acumulação capitalista, com o crescente protagonismo do rentismo, dissolve os laços que soldavam os interesses das

\footnotetext{
${ }^{26}$ Maior desemprego, defendia o autor, conduzia a uma ampliação das desigualdades salariais (e/ou a um aumento das horas trabalhadas, sem promover necessariamente ampliação da taxa salarial das atividades manufatureiras).
} 
empresas do setor produtivo e dos seus trabalhadores no sentido de repartir os frutos dos ganhos sistêmicos de produtividade. Tais ganhos eram repartidos entre aumento de lucros, aumentos dos salários reais e redução da jornada de trabalho (Mattos, 2009), num jogo de "ganha-ganha" somente possível em contexto de prosperidade econômica, ganhos sistêmicos de produtividade (Mattos, 2019; 2009) e de interação entre investimentos privados no setor produtivo e investimentos públicos, sendo que estes, muitas vezes, "puxavam" aqueles, em uma economia “credit-oriented" (Guttmann, 1994), na qual também o setor bancário estava regulado para servir à produção (Plihon, 1996).

O objetivo do pleno emprego, atingido na maioria dos países durante cerca de 25 anos, ampliara o poder de barganha dos sindicatos de trabalhadores, sem necessariamente deprimir, em termos absolutos, os lucros do setor privado empresarial. Desta maneira, conjugavam-se os fatores econômicos, políticos e sociais que abriam espaço para uma melhoria do perfil distributivo destas sociedades, notadamente no que se refere à distribuição da renda pessoal (rendas do trabalho mais rendimentos provenientes de transferências sociais, incluindo as previdenciárias). Não é sem motivo que os anos 1950, 1960 e 1970 exibiram, nos países desenvolvidos, notórios movimentos de redução das desigualdades pessoais de renda (Piketty, 2014; Mattos, 2009; Glyn, 2006). Da mesma maneira, não é por acaso que a adoção de políticas neoliberais (que se constituem, em seu cerne, em ataques às medidas que haviam construído as sociedades de Welfare State) tenha gerado não apenas crescente desigualdade econômica (em suas diversas formas de manifestação) como também deterioração das condições de trabalho.

Nesse contexto, as medidas de flexibilização dos mercados de trabalho foram (e ainda têm sido) adotadas em concomitância com medidas também de desregulamentação dos mercados financeiros internacionais (Mattos, 2009), conferindo ao capital financeiro-especulativo maiores facilidades para se movimentar pelo globo e para captar rendas "fictícias" em ativos financeiros nas diversas praças bancárias, tanto nos países desenvolvidos, como nos periféricos (para não falar dos "paraísos fiscais"). Ao mesmo tempo, os Estados Nacionais (com níveis diferentes de "timing", intensidade e "êxito"27) atuaram no sentido de enfrentar as políticas sociais, reduzindo preferencialmente os gastos públicos destinados a esses mecanismos de geração secundária de renda e/ou de alívio no

\footnotetext{
${ }^{27}$ Do ponto de vista dos interesses do capital.
} 
comprometimento dos orçamentos familiares com gastos em bens e serviços essenciais (Grotti; Scherer, 2016).

A financeirização da renda, percebida tanto nos orçamentos familiares (Piketty, 2014) como nos balanços das empresas (Glyn, 2006; Palma, 2009), refletem as mudanças ocorridas nas últimas décadas na natureza do padrão de acumulação capitalista. A ascensão das finanças, por sua vez, e de forma contraditória com a complexificação das sociedades capitalistas (dada a crescente demanda por democracia, especialmente a partir da reconstrução europeia ou, antes, do New Deal americano), promove uma diversificação das fontes de renda geradas no processo de desenvolvimento econômico dos países. Em diferentes momentos desde o pós-segunda guerra, as diversas crises sistêmicas do capitalismo promoveram mudanças no padrão de acumulação (Streeck, 2018), mas estas mudanças foram sendo implementadas em cenário de crescente desregulamentação dos fluxos financeiros internacionais e de inabalável hegemonia do pensamento liberal-conservador. Desta forma, foram se reforçando mecanismos de concentração da renda e da riqueza e, dentro dessa, da riqueza financeira mais ainda do que a produtiva.

Porém, para que este processo tenha se desenrolado desta forma tão desigual, ele precisou promover a desvalorização do trabalho, notadamente o trabalho formal, que parecia ter se solidificado, nos Anos Dourados, como "norma" das relações de trabalho. Para que esse processo de desigualdade econômica tivesse tido essa trajetória, foi necessário não apenas que os mercados de trabalho fossem "flexibilizados" (Galbraith; Kum, 2002; Galbraith, 2009, 2012), mas também que os orçamentos públicos tivessem uma nova configuração, com a destinação de favores ou benefícios institucionalizados pelas decisões tomadas na esfera da política. Assim, fechava-se o circuito em que "as pessoas dependentes de salário" (Streeck, 2018, p. 106), aquelas que o autor também chama de "povo dos Estados Nacionais europeus" (Streeck, 2018, p. 134), tinham sido vítimas tanto do processo de repartição primária do excedente produtivo como também da repartição secundária, através de novas orientações das políticas públicas e dos gastos definidos nos orçamentos públicos.

Conforme pontuou Galbraith (2009), a flexibilização dos mercados de trabalho são o outro nome do desemprego e este o instrumento pelo qual a renda do trabalho e, por vias institucionais e determinações do funcionamento da política 
(conforme mostraram Streeck (2018) e Bonica et al. (2013)), as rendas oriundas de transferências sociais (e de sua outra face, as "isenções tributárias" ao capital), perdem participação na apropriação dos excedentes gerados pelos ganhos sistêmicos de produtividade (de resto, menores, nos tempos do neoliberalismo do que haviam sido nos tempos do "capitalismo regulado", conforme mostram dados e ponderações de Palma (2009)).

É por isso que a compreensão da natureza da trajetória e do comportamento da desigualdade econômica é fator determinante para entender as transformações ocorridas no mundo do trabalho - e vice-versa. A recorrente precarização do emprego, ao lado da perda de capacidade do capitalismo contemporâneo em gerar ganhos sistêmicos de produtividade (Mattos, 2019; Palma, 2009), acabam abrindo espaço para a instalação do discurso da capitulação dos movimentos sociais e trabalhistas, de resto já enfraquecidos pelas próprias mudanças da natureza da atividade laboral, em ambiente de enfraquecimento dos sindicatos, premidos pela ascensão do conservadorismo político e pelas dificuldades que muitas das novas atividades laborais geram para a organização dos trabalhadores. Nesse ambiente, diminui não apenas a taxa de sindicalização, mas também o grau de cobertura dos acordos coletivos, que eram muito mais altos nos tempos de sociedades industriais em pleno emprego (Glyn, 2009).

As esferas de regulação das sociedades capitalistas, definidas em grande medida pela atividade parlamentar capturada pela ascensão das finanças e da concentração da riqueza, afetam as diversas esferas de determinação da renda, mas têm no mercado de trabalho seu ponto central, a partir do qual, direta ou indiretamente $^{28}$, derivam diversas medidas que impulsionam a desigualdade econômica, em suas mais variadas manifestações.

\section{Conclusões}

As transformações ocorridas na ordem financeira internacional desde o segundo pós-guerra moldaram as mudanças ocorridas no padrão de acumulação capitalista, de tal forma que as estratégias empresariais e as decisões dos

\footnotetext{
${ }^{28}$ As políticas públicas que perfazem os sistemas nacionais de Welfare State estão, em grande medida, ancoradas, notadamente em suas fontes de financiamento, nas relações estáveis de trabalho que foram construídas durante os anos de quase pleno emprego com liderança setorial das atividades manufatureiras nos respectivos mercados de trabalho. Ver: Keztenetzky (2012) e Mattos (2009).
} 
agentes econômicos impactaram também o mundo do trabalho e o perfil distributivo dos países.

A importância de se retomar o debate sobre desigualdade abarca os aspectos mencionados acima, mas também permite, mormente quando são destacados os principais condicionantes do que aqui chamamos de "debate sobre o 1\% do topo", compreender quais aspectos políticos e institucionais também intervieram (e continuam a atuar) para a conformação do comportamento do perfil de distribuição da renda e da riqueza nas últimas décadas. $O$ amadurecimento do "debate sobre o 1\%" é decorrente das evidências empíricas reveladas pelo tratamento dos dados estatísticos sobre renda e riqueza do topo da distribuição, mas também resulta do reconhecimento, por parte da literatura sobre o tema, de que a desigualdade econômica não deveria se ater apenas às rendas do trabalho (ou rendas familiares), como era mais comum em meados do século XX, mas também a outras fontes de rendimentos.

O estudo pormenorizado do perfil dos rendimentos dos ricos e dos muito ricos, sob o Capitalismo Contemporâneo, chamou a atenção para a necessidade de incorporar os aspectos políticos e institucionais atinentes ao funcionamento das respectivas sociedades - o que, por sua vez, ajuda a compreendê-las. Esse esforço de interpretação em torno da complexidade da questão da desigualdade (e, aqui, pensando não apenas em seu aspecto econômico, mas também social) torna-se imperioso à medida que o tema se revela, cada vez mais, conforme reconhecem diversos estudiosos, multidimensional e multidisciplinar. A concentração da riqueza anda junto à concentração do poder político - reforçando-se mutuamente.

Estudos de economistas ${ }^{29}$ que tenham esta visão estrutural e abrangente do fenômeno, como os mencionados neste artigo, trazem um ponto muito importante para a discussão: os efeitos da ordem financeira internacional sobre as políticas macroeconômicas e as estratégias empresariais, conforme procuramos pontuar em diversas partes do artigo. Esta modalidade mais ampla de análise resulta de um reconhecimento de que aspectos microeconômicos, conforme alertam Atkinson (1997) e vários estudos de James Galbraith (o que é muito comum em análises neoclássicas da disciplina de Economia do Trabalho), não são capazes de destrinchar as causas da inaudita expansão recente da desigualdade dentro da maioria dos países, e nem mesmo de explicar porque, em muitos países, a desigualdade econômica se

\footnotetext{
${ }^{29}$ Os economistas políticos, segundo a antiga denominação dessa vertente do pensamento social.
} 
acentuou de forma mais acentuada do que em outros (Galbraith e Piketty, por exemplo, em inúmeros estudos, destacam que, nos EUA, a desigualdade tem crescido muito mais velozmente do que nos demais países desenvolvidos).

É somente sob uma análise estrutural e abrangente da desigualdade que surge o tema do rentismo (ou da "acumulação predominantemente financeira do capital"), fruto das modificações ocorridas na concertação geopolítica da ordem financeira internacional que havia sido construída no pós-segunda guerra. As profundas transformações nos padrões de acumulação de capital, acompanhada também de importantes mudanças (caminhos claramente opostos) na trajetória da desigualdade econômica nos mais variados países, conforme indicam as séries históricas de dados sobre distribuição de renda ao longo do século XX e dos já quase vinte anos do século XXI, revelam a necessidade de se introduzir na discussão da desigualdade outros aspectos que não apenas os econômicos. É preciso ficar claro que o rentismo tem capturado a Democracia, colocando-a à sua disposição. Ou seja, o rentismo, entendido em seu aspecto mais amplo, permite compreender que o mesmo "captura" a própria Democracia para sua sobrevivência e expansão (o que não elimina - pelo contrário - o potencial conflitivo das sociedades atuais).

Procuramos argumentar, portanto, que o rentismo não apenas resulta das mudanças da ordem financeira internacional, mas também que o mesmo opera (e é fruto de) transformações institucionais e políticas no âmbito dos Estados Nacionais para se (re)alimentar, atuando dentro dos Parlamentos e sistemas judiciários dos países, de tal forma a garantir, em seu favor, leis e regulamentações que não prejudiquem (e, se $e$ quando possível, expandam) a magnitude e "estabilidade" (jurídica, inclusive) dos fluxos de rendimentos provenientes da posse de diversos ativos (financeiros ou não-financeiros), tanto dos já existentes, como dos que os "mercados" possam criar. Para isso, são importantes as leis que regulam, em favor do capital, as práticas de acumulação, as relações de capital e trabalho e a concorrência internacional (regida pela "diplomacia financeira internacional" de que fala Streeck, 2018).

Deve-se também deixar claro que a compreensão acerca dos determinantes da desigualdade, em todas as suas vertentes, serve (ou deveria servir...) não apenas aos que se empenham na elaboração de políticas públicas e ao enfrentamento das mazelas sociais, mas também aos que se preocupam em gerar mecanismos para 
dinamizar o Capitalismo, conforme se observa à medida que surgem, tanto no mundo capitalista quanto nos países periféricos, acadêmicos e lideranças políticas ou empresariais comprometidas com essa forma de organização social da produção e que têm manifestado inquietações com a questão da desigualdade extrema ${ }^{30}$ e de seus efeitos econômicos e sociais.

\section{Referências}

AARON, H. Politics and the professors. Washington: Brookings Institute, 1978.

ATKINSON, A. Bringing income distribution in from the cold. The Economic Journal, v. 107, n. 441, p. 297-321. 1997.

ATKINSON, A. Factor shares: the principal problem of political economy? Oxford Review of Economic Policy, v. 25, n. 1, p. 3-16, 2009.

BELLUZZO, L. G. de M. O declínio de Bretton Woods e a emergência dos mercados globalizados. Economia e Sociedade, v. 4, n. 1, p. 11-20, 1995.

BELluZZO, L. G. de M. O despotismo dos estoques. Carta Capital, São Paulo, n. 26, 26 jun. 1996.

BELlUZZO, L. G. de M. O tempo de Keynes nos tempos do capitalismo. São Paulo: Editora Contracorrente, 2016.

BLUESTONE, B.; HARRISON, B. The Great U-Turn: Corporate Restructuring And The Polarizing Of America. Nova Iorque: Basic Books, 1988.

BONICA, A.; MCCARTHY, N.; POOLE, K.; ROSENTHAL, H. Why hasn't democracy slowed rising inequality? Journal of Economic Perspective, v. 27, n. 3, p. 103-124, 2013.

\footnotetext{
${ }^{30}$ Reportagem no jornal Valor Econômico de 25 de junho de 2019 (p. A10) informa que 19 milionários dos EUA (entre eles, George Soros e a herdeira da Disney, Abigail Disney, como também Chris Huges, um dos cofundadores da Google) sugerem um imposto sobre os muito ricos, que gere recursos para financiar projetos de controle de mudança climática e de saúde pública. Estas pessoas estão também preocupadas com a intensa e crescente desigualdade nos EUA. Eles redigiram uma carta aberta, pedindo a todos os candidatos a Presidente, sejam eles republicanos ou democratas, que apoiem a adoção de um imposto moderado sobre fortunas para os $1 / 10$ dentro os $1 \%$ mais ricos dos americanos. Vale citar um trecho da matéria: "Uma das pessoas mais jovens signatárias, Liesel Simmons, dona de um patrimônio avaliado em US\$ 33 bilhões, definiu assim a situação: 'Somos parte do problema; portanto, taxem-nos"”.

Os signatários defendem que esta carta dê início a um debate sobre a questão da desigualdade entre os candidatos a Presidente em 2020. Para registro, deve-se também mencionar que os economistas André Lara Resende e Armínio Fraga têm revelado preocupações com a questão da desigualdade extrema no Brasil.
} 
CHESNAIS, F. A mundialização do capital. São Paulo: Xamã, 1996a.

CHESNAIS, F. Mondialisation financière et vulnérabilité systemique. In: CHESNAIS, F. La mondialisation financière: genèse, coût et enjeux. Paris: Syros; $1996 b$.

CHESNAIS, F. Mundialização do capital, regime de acumulação predominantemente financeira e programa de ruptura com o neoliberalismo. Revista da Sociedade Brasileira de Economia Política, v. 3, n. 1, p. 7-34. 1997.

CHESNAIS, F. A teoria do regime de acumulação financeirizado: conteúdo, alcance e interrogações. Economia e Sociedade, v. 11, n. 1, p. 1-14. 2002.

DALTON, H. The measurement of the inequality of incomes. The Economic Journal, v. 30, n. 119, p. 348-361, 1920.

DEDECCA, C. Trabalho, financeirização e desigualdade. Texto para Discussão, IE/UNICAMP, n. 174, 2010.

DEDECCA, C. Desigualdade, mas de qual falamos? Revista de Economia Política, v. 32, n. 1, p. 55-71, 2012a.

DEDECCA, C. Os países desenvolvidos e a desigualdade econômica. Economia e Sociedade, v. 21, n. 3, p. 449-484, 2012 b.

EPSTEIN, G. Financialization and the world economy. Cheltenham, Elgar, 2005.

EUBANKS, V. Automating inequality - how high-tech tools profile, police, and punish the poor. Nova Iorque: St. Martin's Press, 2017.

GALBRAITH, J. K. A Perfect Crime: Inequality in the Age of Globalization. Daedalus, v. 131, n. 1, On Inequality (Winter, 2002), p. 11-25. The MIT Press on behalf of American Academy of Arts \& Sciences.

GALBRAITH, J. K. Inequality, unemployment and growth: new measures for old controversies. Journal of Economic Inequality, n. 7, p. 189-206, 2009.

GALBRAITH, J. K. How economists have misunderstood inequality: an interview with James Galbraith. The Washington Post, May 3, 2012. Disponível em: https://www.washingtonpost.com/blogs/ezra-klein/post/how-economists-havemisunderstood-inequality/2012/05/03/gIQAOZf5yT_blog.html?noredirect=on\& utm_term=.10704807a5f9.

GALBRAITH, J. K. Inequality: what everyone needs to know. Oxford: Oxford University Press, 2016a. 
GALBRAITH, J. K. Causes of Changing Inequality in the World. Intereconomics, v. 51, n. 2, p. 55-60, 2016 b.

GALBRAITH, J. K. Extreme inequality creates global disorder: and it's a problem that can only have a political solution. The Nation, June 22, 2018. Disponível em: https://www.thenation.com/article/archive/extreme-inequality-creates-globaldisorder/.

GALBRAITH, J. K. A global macroeconomics - yes, macroeconomics, dammit of inequality and income distribution. Review of Keynesian Economics, v. 7, n. 1, p. 1-5, 2019.

GALBRAITH, J. K.; KUM, H. Inequality and economic growth: data comparisons and econometric tests. UTIP Working Paper Number 21, p. 1-19, 2002.

GALBRAITH, J. K. The affluent society. Boston: Mariner Books; 1998 [1958].

GLYN, A. Capitalism unleashed: finance, globalization and welfare. Oxford: Oxford University Press, 2006.

GOLDFARB, R.; LEONARD, T. Inequality of what among whom? Rival conceptions of distribution in the 21th century. Research in the History of Economic Thought and Methodology, v. 23-A, p. 79-123, 2005.

GROTTI, R.; SCHERER, S. La disugualianza economia tra contesti: il ruolo di famiglia, stato e mercato. Sociologia del lavoro, n. 143, p. 57-75, 2016.

GUIMARÃES, J. The high cost of inequality in rich countries. Development and Change v. 43, n. 5, p. 1159-1169. 2012.

GUTTMANN, R. How credit-money shapes the economy. Nova Iorque: M.E.Sharpe, 1994.

HACKER, J.; PIERSON, P. Winner-take-all politics: public policy, political organization, and the precipitous rise of top incomes in the United States. Politics \& Society, v. 38, n. 2, p. 152-204, 2010.

HOBSBAWM, E. Era dos extremos: o breve século XX (1914-1991). São Paulo: Companhia das Letras, 1995.

ILO, 2007. Equality at work: tackling the challenges. International Labour Conference. Genebra, 2007. 
JANSSON, B. The reluctant Welfare State: engaging history to advance social work practice in contemporary society. Belmont: Brooks/Cole, 2009.

JENCKS, C. Does inequality matter? Daedalus, v. 131, n. 1, p. 49-65, 2002.

KEISTER, L. The one percent. Annual Review of Sociology, v. 40, n. 3, p. 47-67, 2014.

KERSTENETZKY, C. O estado do bem estar social na idade da razão: a reinvenção do estado social no mundo contemporâneo. Rio de Janeiro: Elsevier Editora, 2012.

KUZNETS, S. Economic growth and income inequality. American Economic Review, v. 45, n. 1, p. 1-28, 1955.

MARX, K. O capital - crítica da economia política. Rio de Janeiro: Civilização Brasileira, 1968 [1867].

MATTOS, F. A. M. Lições do capitalismo organizado: o mercado de trabalho do Pós-Guerra nos países capitalistas centrais. Ensaios FEE, v. 18, n. 1, p. 122-147, 1997.

MATTOS, F. A. M. Flexibilização do Trabalho: sintomas da crise. São Paulo: Ed. Annablume, 2009.

MATTOS, F. A. M. Desigualdade e repartição dos ganhos de produtividade horária do trabalho nos países capitalistas centrais. Anais do XVI Encontro Nacional da Associação Brasileira de Estudos do Trabalho. Salvador (BA), 2019.

MILANOVIC, B. Why we all care about inequality (but are loath to admit it). Challenge, v. 50, n. 6, p. 109-120, 2007.

MOFFITT, M. O dinheiro do mundo - de Bretton Woods à beira da insolvência. Rio de Janeiro: Ed. Paz e Terra, 1984.

NOAH, T. The great divergence: America's growing inequality crisis and what we can do about it. Nova Iorque: Bloomsbury Press 2010.

OECD. Growing unequal? - income distribution and poverty in OECD countries. Paris: OECD, 2008.

PALMA, J. Globalizing inequality: 'centrifugal' and 'centripetal' forces at work. DESA Working Paper n. 35, 2006. 
PALMA, J. The revenge of the market on the rentiers. Why neo-liberal reports of the end of history turned out to be premature. Cambridge Journal of Economics, v. 33, n. 4, p. 829-869. 2009.

PALMA, J. Homogeneous middles vs. heterogeneous tails, and the end of the 'inverted-U'. Development and Change, v. 42, n. 1, p. 87-153, 2011.

PIKETTY, T. O capital no século XXI. Rio de Janeiro: Intrínseca, 2014.

PIKETTY, T. Capital and ideology. Cambridge: Harvard University Press, 2019.

PIKETTY, T.; SAEZ, E. Top incomes and the great recession: recent evolutions and policy implications. IMF Economic Review, v. 61, n. 3, p. 456-478, 2013.

PLIHON, D. Desequilíbrios mundiais e instabilidade financeira. (A responsabilidade das políticas liberais: um ponto de vista keynesiano). Economia e Sociedade, v. 5, n. 2, p. 85-127, 1996.

REICH, R. How inequality erodes the foundation of modern societies. New York Times, July 20, 2017. Disponível em: https://www.nytimes.com/2017/07/20/books/review/the-fate-of-the-west-billemmott-one-anothers-equals-jeremy-waldron-.html.

STIGLITZ, J. The price of inequality: how today's divided society endangers our future. Nova Iorque: W.W. Norton \& Company, 2013.

STREECK, W. Tempo comprado: a crise adiada do capitalismo democrático. São Paulo: Boitempo, 2018.

THERNBORN, G. The killing fields of inequality. Cambridge: Polity Press; 2013.

UNITED NATIONS. The inequality predicament. New York: United Nations, 2005.

WADE, R. Is globalization reducing poverty and inequality? World Development, v. 32, n. 4, p. 567-589, 2004.

WADE, R. Does inequality matter? Challenge, n. 48, n. 5, p. 12-38, 2005.

WADE, R. Global trends in income inequality: what is happening, and should we worry? Challenge, v. 54, n. 5, p. 54-75, 2011.

WADE, R. Why has income inequality remained on the sidelines of public policy for so long? Challenge, v. 55, n. 3, p. 21-50, 2012. 
WADE, R. The strange neglect of income inequality in economics and public policy. In: CORNIA, G.; STEWART, F. (Eds.). Towards human development: new approaches to macroeconomics and inequality. Oxford: Oxford University Press, 2014, p. 99-121.

WINTERS, J. Oligarchy. Cambridge: Cambridge University Press, 2011. 